\title{
INVESTIGACIÓN/RESEARCH
}

\section{LA PERSPECTIVA. DEL RENACIMIENTO AL 3-D}

José-María Castillo-Pomeda. Universidad Francisco de Vitoria (España)

Miguel Ángel Ortiz Sobrino. Universidad Francisco de Vitoria (España)

\section{Introducción}

El concepto de perspectiva nos es hoy tan familiar que incluso lo empleamos en el lenguaje coloquial o periodístico, a veces sin demasiada fortuna. Todos sabemos que perspectiva es el "punto de vista", la profundidad, la lejanía... Sin olvidar que la "perspectiva aérea" no es ver el paisaje desde un avión...

La aparición de la fotografía, a principios del siglo XIX, no hizo sino consagrar lo que la cámara oscura, vía pintores post renacentistas (Vermeer, Canaletto, Velázquez, etc.) ya habían impuesto: la perspectiva central o artificialis, inventada por el arquitecto Brunelleschi, que los modernos hiperrealistas, recuperaron para la pintura después de la reacción de las vanguardias de la primera mitad del siglo XX.

El rodaje de Alas de Coraje, hace ya cinco años, fue la señal de que la industria del cine va a volver a desempolvar el varias veces emprendido y otras tanas desechado, camino del 3-D. Eso tendrá unas consecuencias para empleo de la perspectiva que ahora es pronto para evaluar pero que probablemente, esté en el acierto de su tratamiento la supervivencia o no de este nuevo intento. Hasta principios del Quatrocento, los pintores no reflejaban en sus cuadros la realidad tal como se ve, sino que pintaban lo que "era conveniente o necesario".

El arquitecto Bruneleschi se encuentra con la necesidad de mostrar gráficamente el aspecto que iban a tener sus proyectos o, más simple, necesita que los maestros de obra interpreten sus intenciones sin dudas y "se ve obligado a inventar" un sistema geométrico proyectivo al que denomina "perspectiva artificialis". Nos encontramos así, con la curiosidad de que el sistema de representación empleado a partir de entonces por todos los pintores realistas (y fotógrafos y cineastas) no lo inventa un pintor, sino un arquitecto.

\section{Metodología}

La base metodológica sigue una línea diacrónica en el estudio y aplicación de la perspectiva por los artistas, desde el Renacimiento hasta nuestros días. Se analiza esta evolución y las técnicas empleadas, llegando a conclusiones que dejan abierto el camino a un nuevo planteamiento de los métodos de representación de la 
perspectiva que, no es demasiado atrevido pronosticar, propiciarán las técnicas del 3-D.

\section{Análisis y discusión:}

\subsection{El renacimiento y la perspectiva}

La perspectiva artificialis o lineal consiste en contemplar el objeto a representar centrado desde una altura media, a partir de un punto único que que equivale a mirar con un sólo ojo. De esta forma se supera la bidimensionalidad medieval para entrar en una forma de representar la realidad como como si la viésemos a través de una ventana. Esto conmociona el mundo de la pintura: Masaccio, pintor de moda, realiza un alarde visual, que se convierte en toda una declaración de intenciones. Su "Trinidad", (en el que parece intervino el propio Brunellesqui) abre una fingida capilla en el muro de la iglesia de Santa maría Novella (Florencia). Se trata de un fresco que representa el misterio de la Trinidad, con la imagen de las tres Personas a tamaño natural. Este atrevimiento formal alcanza una formidable repercusión, comparable a la de los primeros impresionistas o a la aparición del cubismo. Era toda una revolución en la forma de lectura de la imagen y el aprendizaje de este nuevo modo de ver no resultó sencillo.

Pero estamos en la época de la curiosidad científica y, paulatinamente, van apareciendo descubrimientos que los pintores van haciendo suyos: las leyes de la óptica ponen orden en los tamaños de los objetos más o menos próximos y, sobre todo, llevan ese orden al terreno de la geometría. El tamaño de las cosas no depende del capricho o el interés del artista, sino de su distancia al ojo que escruta la realidad. El objeto lejano ha de ser pequeño y menos nítido en una cuantía determinada exactamente por la geometría y la matemática. Aparece así el concepto de "tercera dimensión", de profundidad, siendo en este aspecto fundamental la aplicación de la sección áurea, también redescubierta en el Quatrocento por el colaborador de Leonardo, el fraile Lucca Paccioli.

Son varios los mecanismos que consagran la tercera dimensión y que los pintores renacentistas incorporan a sus obras:

1. Los fondos dejan de ser planos para pasar a tener volumen (paisajes, interiores con detalle) de forma que el espacio que rodea a la figura, se vuelve profundo en su relación con esta.

2. El uso de las gamas tonales y el dominio de las sombras, que se perfeccionan en el Trecento, potencian los efectos de volumen, masa y peso de las figuras.

3. Se va dando forma a todo un corpus teórico, que sustenta los descubrimientos empíricos realizados en los talleres. Aparecen varios tratados sobre la nueva forma de ver, escritos por los propios artistas o por sus mecenas, en los que se difunden sus secretos a la vez que se apróximan al mundo de la ciencia. 
Brunelleschi entiende por primera vez la arquitectura como la ciencia el espacio y así, la perspectiva supera el ámbito pictórico para constituirse en base de todas las artes del diseño: pintura, escultura, arquitectura y escenografía.

Las leyes de la perspectiva son finalmente recopiladas y sistematizadas por León Baptista Alberti en el tratado "De pictura" (De la pintura) (1436). Aquí se establecen, de forma sistemática, los principios matemáticos de la perspectiva y aparece por primera vez el concepto de "ventana", a través de la cual se contempla la escena. Aunque Alberti dirige sus consejos a sus colegas pintores pero, como advierte al comienzo de la obra, "toma de los matemáticos todo aquello que conduzca a su propósito".
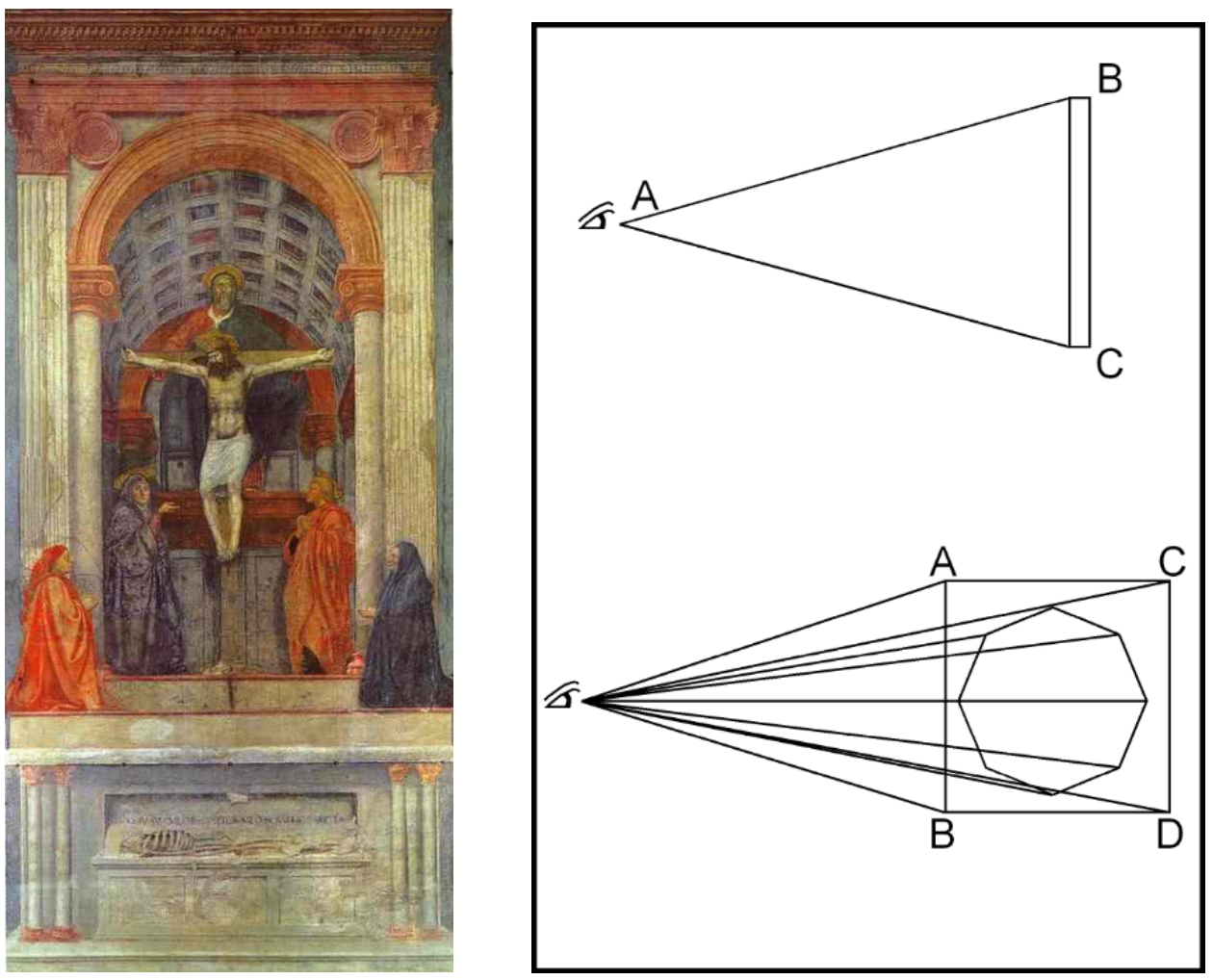

FIG. 1. Masaccio. La Trinidad. 1426-28. Fresco. Santa Maria Novella, Florencia

FIG. 2 La "pirámide de la visión" de Alberti

Alberti basa su método en el que ya se venia empleando en los talleres pero, dejando de lado los sistemas artesanales, traza en primer lugar la línea de base para después establecer el punto de fuga. Esta línea de base se divide en partes iguales y se trazan las líneas hacia dicho punto de fuga.

La "ventana" no hace sino cortar en un plano la pirámide, mostrando la proporción de las cosas en razón a la distancia. Pero en realidad hay dos pirámides. La primera es la mencionada por Alberti, pero a ella se suma una segunda pirámide formada por la disminución progresiva de tamaño de los objetos desde los bordes de la imagen hacia el punto de fuga. Las dos pirámides tienen un eje común: el que une sus vértices, y están unidas por la base, que constituye la superficie del cuadro. 


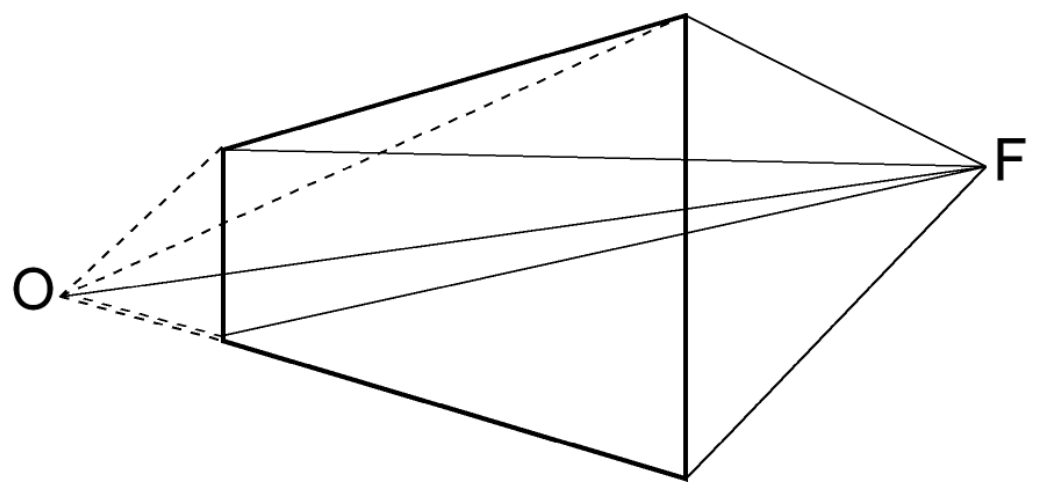

FIG.3.La representación en perspectiva se construye en base a una doble pirámide.

La primera tiene su vértice en la posición del observador $(\mathrm{O})$, mientras el de la segunda se sitúa en el punto de fuga $(F)$

Todo esto se basa en dos premisas fundamentales:

a) Observamos el mundo con un solo ojo, pues a efectos prácticos, los dos ojos están tan juntos que se pueden considerar como uno solo.

b) El ojo del observador o sea, el punto de vista, permanece inmóvil y es el mismo para el pintor y para el espectador. (Alberti, 1435).

La "perspectiva artificialis" presupone un mecanismo de la visión con un punto de vista único e inmóvil; es decir, se coloca en un plano de abstracción con respecto a las condiciones naturales de la visión. Se ha dicho que es un sistema perspectivo de tuertos y de cojos, porque presupone una visión monocular e inmóvil; además, ignora la curvatura del campo visual, conocida desde la antigüedad. La perspectiva lineal constituye una creación mental y abstracta, un "modo de ver" y de construir la pintura que han estado en vigor hasta la ruptura de este espacio plástico a finales del sigo XIX.

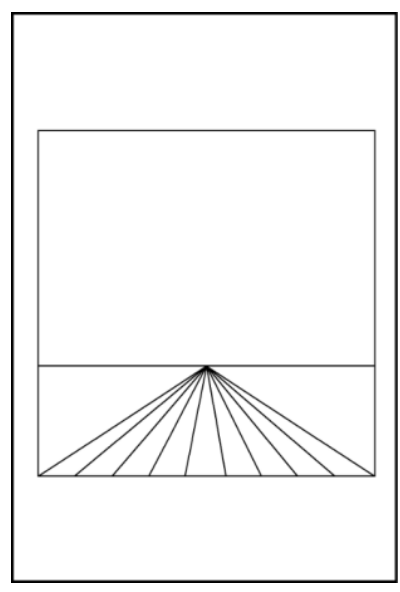

FIG.4. Establecimiento de la línea de base y trazado de las líneas de profundidad 
Piero della Francesca da un paso más y en su tratado "De Prospectiva Pingendi" (1475), trasciende de la pura teorización de Alberti a la demostración practica de teoremas geométricos orientados a la representación pictórica. Piero della Francesca realiza el "efecto ventana" mediante la presencia constante de elementos arquitectónicos en sus pinturas y no utiliza el punto de fuga central.

En oposición a la "Óptica" de Euclides, la proposición V del libro I del De prospectiva pingendi establece implícitamente que las magnitudes aparentes son inversamente proporcionales a la distancia a que se presentan a la vista.

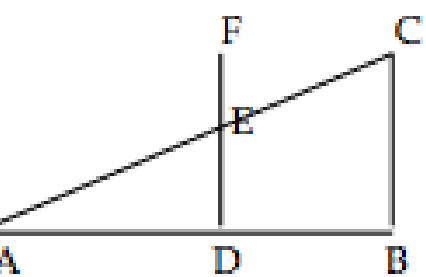

$\mathrm{Si} \mathrm{FD}=\mathrm{CD}$ se tiene:

$$
\begin{aligned}
& \mathrm{EC} / \mathrm{AE}=\mathrm{FE} / \mathrm{DE} \\
& \mathrm{ED} / \mathrm{AD}=\mathrm{FE} / \mathrm{BD} \\
& \mathrm{AC} / \mathrm{AE}=\mathrm{CB} / \mathrm{ED} \\
& \mathrm{FE} / \mathrm{AD}=\mathrm{ED} / \mathrm{BD}
\end{aligned}
$$

Lo que confirma explícitamente la proposición XII del mismo libro según la cual, en las superficies puestas en perspectiva, su disminución es función de la distancia a que se sitúe el plano de intersección (Damisch, 1997).

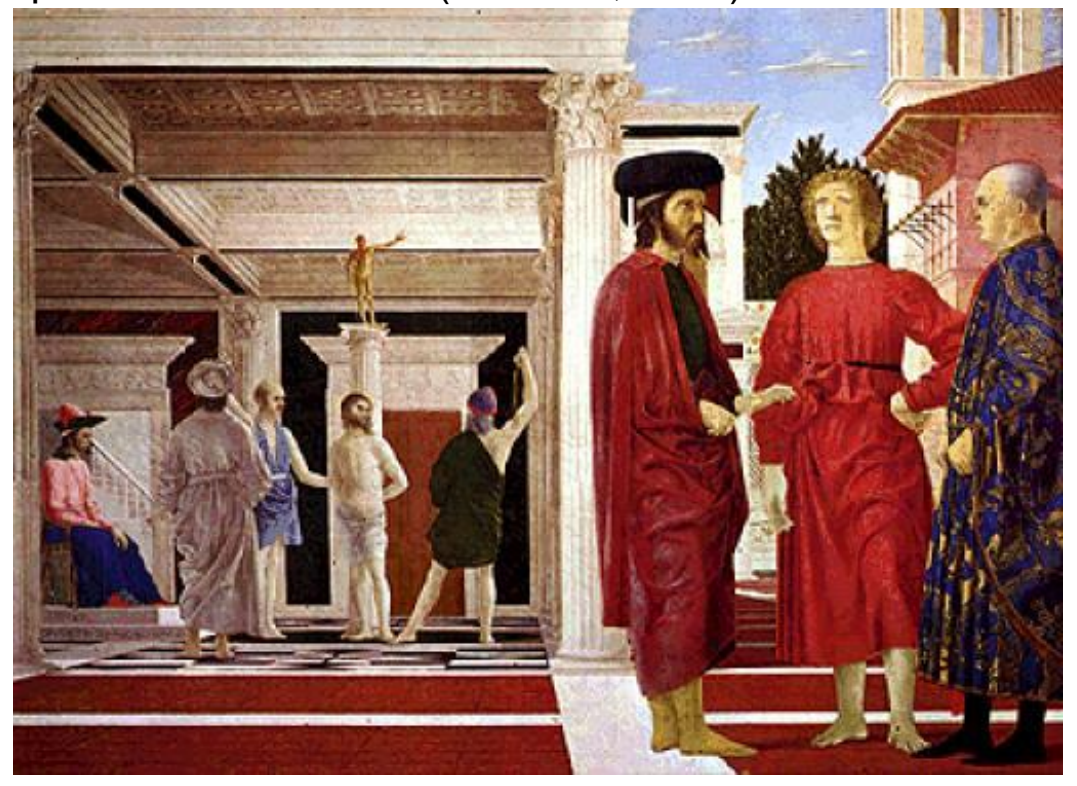

FIG. 6. Piero della Francesca. La Flagelación de Cristo (1445)

La división de la superficie pictórica en dos partes es llevada a cabo mediante el empleo de elementos arquitectónicos. La forma predilecta es una galería abierta, donde una de sus columnas constituye el elemento de disección, que a veces va 
unido a un edificio que se prolonga hacia el fondo. Encontramos un claro ejemplo de esto en La Flagelación de Cristo (1445), donde la disposición geométrica es evidente. Pero aun reconociéndole a Piero della Francesca ser el primero en emplear la perspectiva con todos su matices técnicos, el resultado adolece de un exceso de irrealidad geométrica y de falta de atmósfera, a pesar de lo cual su influencia es decisiva en los pintores posteriores.

Pero será Leonardo da Vinci, el que lleve el estudio y la realización de la perspectiva a su máxima cota. En sus "Cuadernos" encontramos numerosas alusiones a su estudio y a sus estudiosos. En su "Tratado de la Pintura" (Da Vinci, 1784) escribe:

La perspectiva no es otra cosa que ver un lugar a través de un vidrio plano y perfectamente translucido sobre cuya superficie han sido dibujados todos los cuerpos que están del otro lado del cristal. Estos objetos pueden ser conducidos hasta el punto del ojo por medio de pirámides que se cortan en dicho vidrio.

Este sistema de representación recibe los nombres de perspectiva lineal, central o cónica, puesto que por lo general la forma de la proyección no es un polígono sino un circulo y la clave de su verismo radicaba en que los rayos de luz que llegaban a los ojos eran iguales si se miraba directamente al objeto que si se contemplaba la

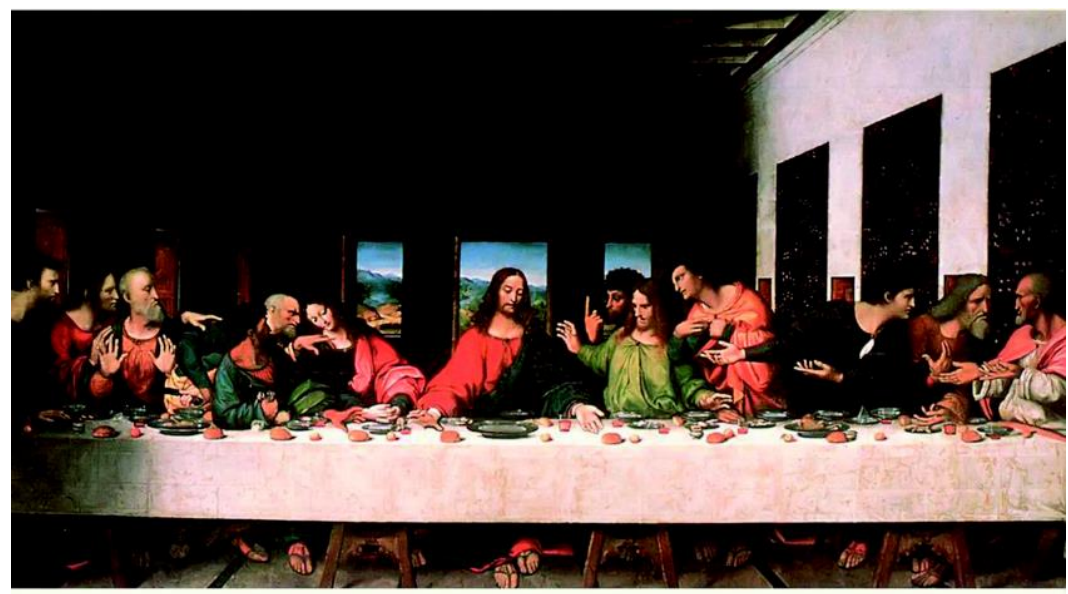

FIG. 7. Leonardo da Vinci. La ultima Cena (1498)

reproducción en perspectiva, es decir, se hacían coincidir los puntos de vista del pintor y del observador. La obra de Leonardo nos deja numerosos ejemplos del empleo de la perspectiva como artificio geométrico-matemático para representar el espacio en dos dimensiones. Pero su mayor aportación es el invento (o la reflexión sobre el fenómeno y su sistematización) de la llamada perspectiva aérea:

Para Leonardo todos los objetos que vemos se encuentran inmersos en el aire, y todas las relaciones de luz, color y distancia dependen de el. La visión empírica demuestra que la distancia, a causa del aire interpuesto y de la agudeza visual, borra y modifica los contornos de las cosas: por su parte, los colores disminuyen su intensidad a medida que aumenta la distancia o el aire se hace más denso, tomando un tono azulado.

El tratado de Leonardo clasifica la perspectiva en tres partes: 
La primera solamente comprende la construcción lineal de los cuerpos; la segunda, la "difuminación" de los colores en relación a las diversas distancias, y la tercera, la pérdida de determinación de los cuerpos en relación a las diversas distancias.
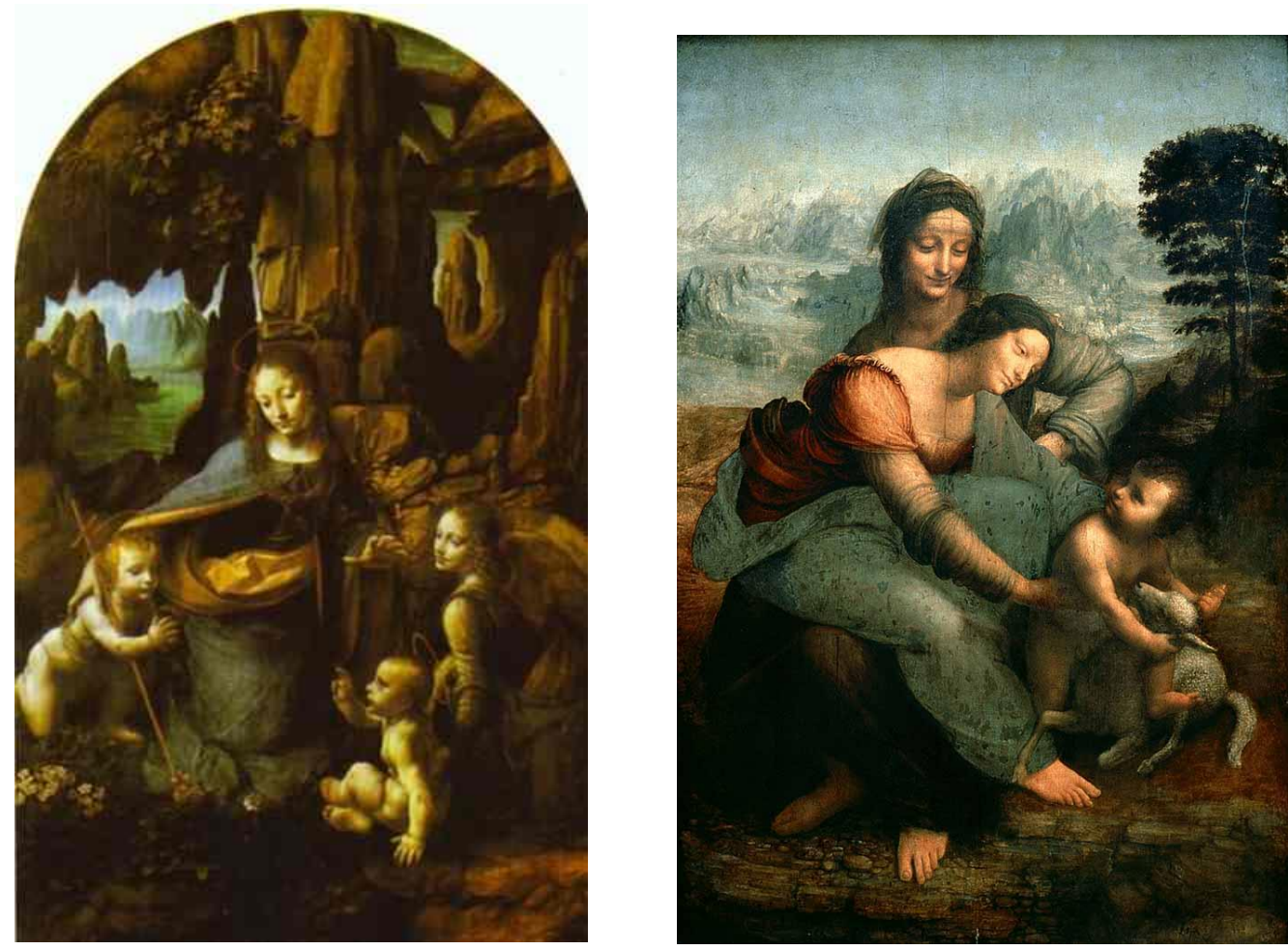

FIGS. 8 y 9. Virgen de las Rocas (1506) y La Virgen y el Niño con Santa Ana

(1510)

Esta "difuminación" (su famoso "sfumato") de los colores y contornos, añadidos a la perspectiva puramente lineal, darán origen a una nueva forma de entender la perspectiva, a la que Leonardo llamará "perspectiva aérea". En otra parte de su tratado escribe:

Hete aquí una otra perspectiva que llamo aérea, pues por la variedad del aire podemos conocer las diversas distancias de los distintos edificios... Habrás, pues, de pintar el edificio más lejano, menos perfilado y más azulado.(Da Vinci, 1784).

Podemos observar este efecto en muchas de sus obras. Destacan a este respecto "La virgen de las Rocas", en la que la salida de la gruta da paso a un fondo azulado, y en La Virgen y el Niño con Santa Ana, en donde el efecto de perspectiva aérea es, asimismo, notable.

Leonardo conocía los textos de óptica existentes en su época, como los de Al Hazen y Pecham. Sus propios cuadernos de notas contienen numerosas entradas sobre la obtención de imágenes mediante cámara estenopeica (imagen invertida que se obtiene al practicar un minúsculo orificio en una caja), la inversión de las imágenes, la forma y el tamaño óptimos del orificio. Extiende sus estudios a la no interferencia de las imágenes dentro del ojo, cosa que demuestra mediante una cámara oscura, así como realiza interesantes estudios sobre el color y sus mezclas auxiliándose de 
este mismo artilugio en "De la naturaleza de los rayos de que las imágenes de cuerpos están compuestas y sus situaciones".

Aunque no hace referencia explicita al uso de los espejos como instrumento óptico, si diseñó maquinas para esmerilar y pulir espejos cóncavos con resultados notablemente mejores que los sistemas manuales. Todo hace pensar que si diseñó maquinaria para construir espejos, realizaría estudios sobre ellos y sus aplicaciones ópticas, aunque pueden estar entre las numerosas notas que se han perdido. En sus cuadernos de notas datados en 1508-1510 desarrolla la analogía entre la cámara oscura y el ojo, además de detallados estudios sobre el comportamiento de las sombras (distancia, dureza, gradación).

Si observamos que el propio Leonardo trabajó en desarrollar el concepto de perspectiva hasta consagrarlo y en los instrumentos ópticos que permitieron resolverla, parece poco lógico que no los aplicara el mismo en su obra pictórica. Así nos explicaríamos el realismo extraordinario que presentan sus imágenes en contraste con las de sus inmediatos antecesores y muchos de sus contemporáneos. También el misterioso "sfumato" podría tener su origen en una imagen producida u observada a través de una lente no demasiado perfecta, que produjera lo que los fotógrafos actuales denominan "foco suave". En cualquier caso, es seguro que Leonardo obtuvo una verificación muy satisfactoria de sus ideas sobre la perspectiva, gracias al empleo de la cámara. En una de sus anotaciones en el "Tratado de la pintura" dice:

Las imágenes de múltiples y distintos cuerpos se reproducen en un agudo orificio a través del cual, y por medio de líneas que, cortándose, generan pirámides contrarias, se proyectan cabeza abajo sobre la primera pared obscura. (Da Vinci, 1784).

La influencia de Leonardo no sólo se manifiesta en sus enseñanzas técnicas, sino en la forma "fotográfica" de ver el mundo, debida sin duda a la aplicación de los descubrimientos que realizó en su faceta de científico.

Alberto Durero (1471-1528) pintor alemán nacido en Nuremberg, toma contacto con la perspectiva en su estancia en Venecia y se convierte en uno de los máximos exponentes de su uso. Escribe varios tratados entre los que debemos recordar "El arte de las medidas" y "Enseñanza de la medida con el compás y la regla en líneas, superficies y cuerpos enteros".

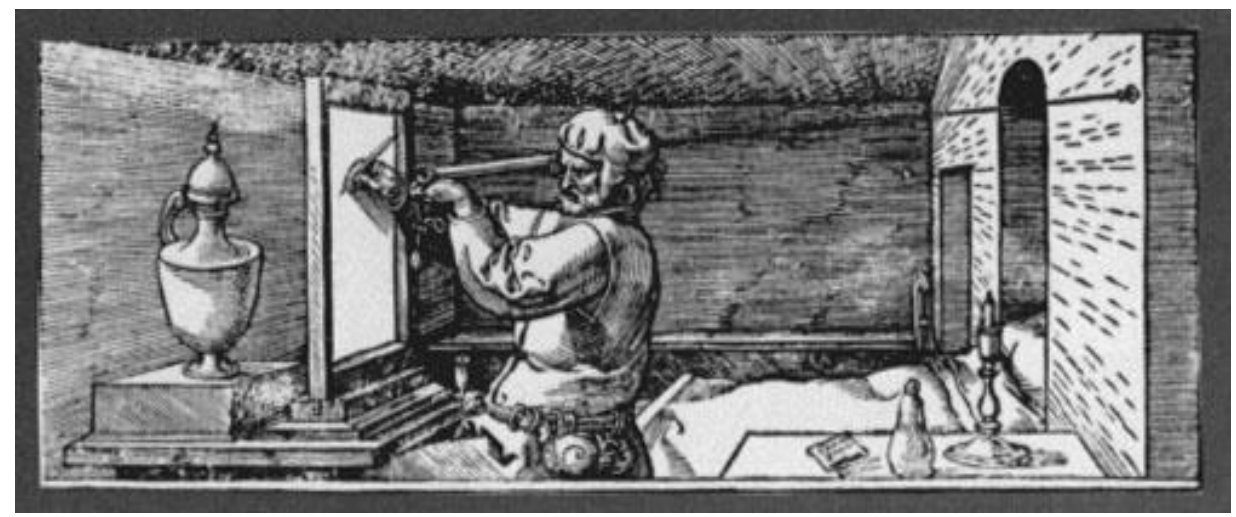

FIG.10. Grabado de Durero en el que ilustra la técnica del dibujo en perspectiva 


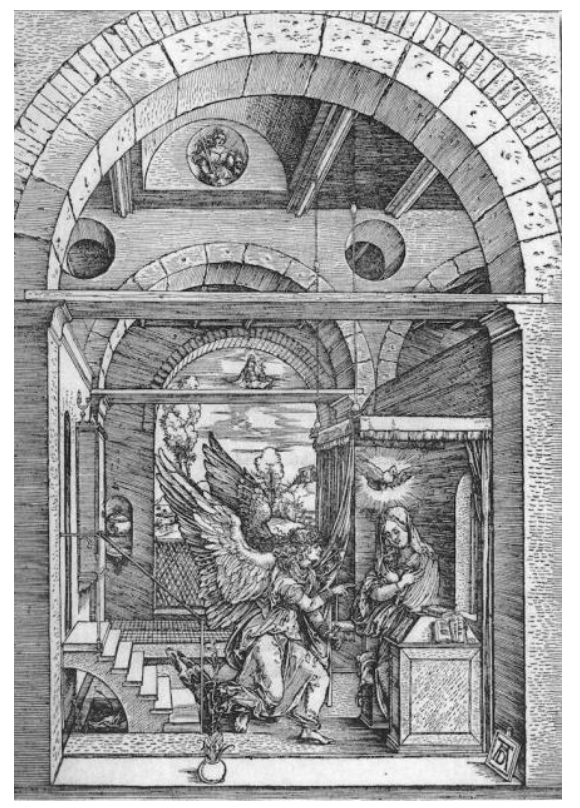

FIG. 11. Durero. La Anunciación

Su obra deja numerosos ejemplos de la perfección a la que llega en el tratamiento de la perspectiva.

\subsection{Evolución del concepto de perspectiva}

Tras la escuela veneciana, la heredera de la perspectiva aérea será la pintura barroca, en la que destacan grandes maestros como Velázquez y Rembrandt, que merecen un estudio pormenorizado.

Pero será el filosofo y matemático francés Rene Descartes quien, ya en el siglo XVII, demuestre de forma empírica (observando la imagen que se formaba en la retina del ojo de un buey recién muerto) que la perspectiva no era una elucubración de geómetras y que respondía a la visión natural del ojo. O sea, que también el ojo se comportaba como un plano que cortaba los rayos de la pirámide... con la salvedad de la curvatura de su fondo. En la Geometría estudia los óvalos, que, en la óptica, utiliza para hacer lentes, en la Dióptrica da las leyes matemáticas de la reflexión y de la refracción, y en los Meteoros las usa para explicar el porqué del arco iris.

Ya para entonces, el astrónomo alemán Johannes Kepler había publicado (1610) su tratado sobre la visión, en el que asemeja el funcionamiento del ojo con el de una cámara oscura (artilugio que llevaba bastante tiempo funcionando en manos de los pintores) y se había superado el cubo escénico, en el cual las caras frontales permanecen como rectángulos paralelos y solo las laterales sufren la transformación en trapecios. 


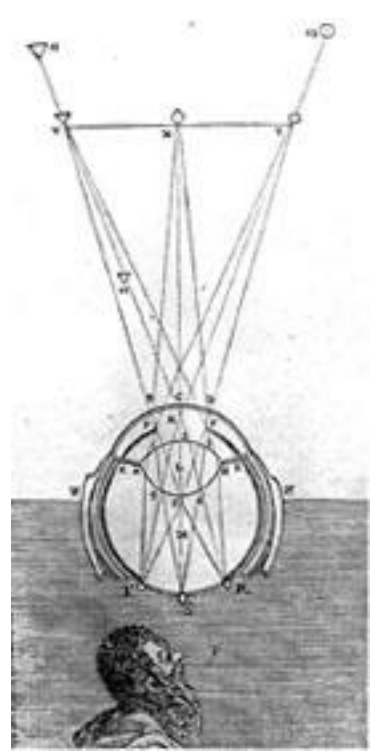

FIG.12. La visión del ojo humano según Descartes (Tratado de la Dioptrique)

Es en el siglo XVI cuando los pintores comienzan a trazar perspectivas con visión oblicua, con dos puntos de fuga, convirtiéndose los rectángulos en trapecios y con los personajes en escorzo, como en "La boda campesina", de Brueghel el viejo (Torán, 1998)).

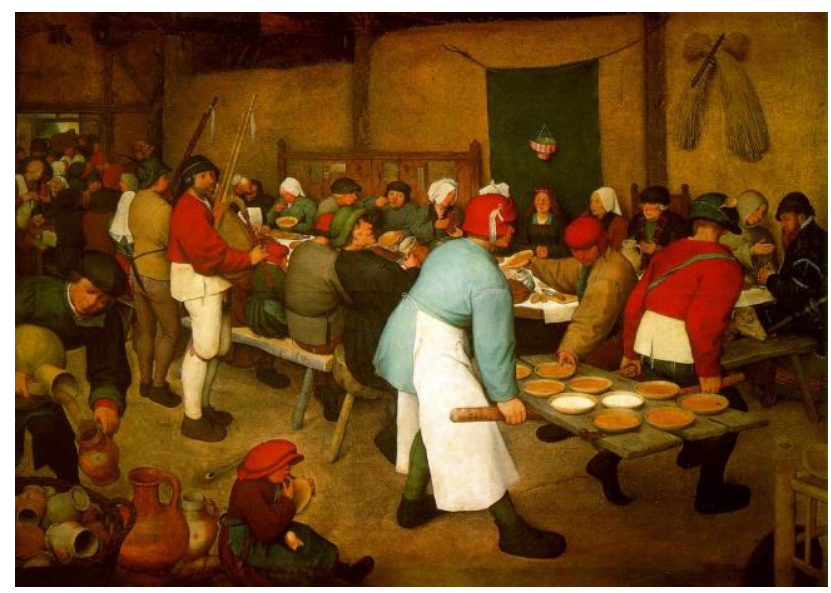

FIG. 13. P. Brueghel. La Boda campesina. Kunsthistorisches Museum, Viena

Se impone la concepción racionalista de la visión a partir de un eje central, que se establece entre el ojo del observador y el punto de fuga, que representa el infinito y alrededor del cual se ordenan los elementos del espacio visual, el mundo, en suma.

A principios del siglo XIX el modelo cartesiano racionalista entra en crisis (comienza a considerarse la percepción como algo subjetivo y tienen lugar las primeras investigaciones sobre la psicología de la percepción) pero paradójicamente, el invento de la fotografía primero y después el del cine, consagran la perspectiva geométrica.

\subsection{Aparición de la fotografía y reacción de las vanguardias}

Precisamente la aparición de la fotografía va a ser decisiva en la concepción, no solo de la perspectiva, sino de la forma de entender la proyección del punto de vista. Surge una bifurcación en el camino de la forma de ver y mientras la fotografía asume 
el planteamiento de mostrar la realidad tal como el ojo la ve, la pintura experimenta otros caminos.

Primero, los impresionistas asumen el concepto fotográfico de detención del instante (no olvidemos que la primera exposición impresionista se realizó en el estudio del fotógrafo Nadar en 1874) aplicándolo a la captación del momento lumínico. Los impresionistas enriquecen extraordinariamente la perspectiva aérea, al precio de convertir la luz en protagonista principal de sus cuadros. Al mismo tiempo, la perspectiva lineal se vuelve en ellos imprecisa, en razón de las manchas de color en que se han disgregado los objetos representados.

Múltiples controversias se desatan en esta época sobre la "artisticidad" de la fotografía y la legitimidad de su uso por los pintores como herramienta auxiliar. Pero la fotografía terminará imponiéndose como notario de la realidad. Aparece el concepto de punto de vista multifijo, que consiste en la plasmación sobre el plano de un proceso natural: la visión multifija, es decir la sucesiva captación de diversas facetas de un mismo sujeto mediante el movimiento de nuestros ojos, cabeza o cuerpo, que da lugar a una imagen con diversos puntos de vista del mismo objeto. Mientras que la representación en perspectiva permite al espectador observar el conjunto y su detalle, tomado en un momento determinado desde un punto de vista, la representación compuesta, nos comunica una mayor impresión de dinamismo de la visión, ofreciéndonos una más completa información de la imagen. Este método multifijo de la visión, aplicado frecuentemente en la obra de Paul Cezanne, fue seguido por otros pintores (Braque, Picasso, Gris) dando paso al movimiento que conocemos con el nombre de cubismo. Detrás llegan el resto de movimientos que se ha dado en llamar "vanguardias", que no sólo se olvidan de la perspectiva, sino que dejan el testigo del realismo a los fotógrafos y se lanzan a explorar caminos que les alejan dela figuración y que no son nuestro tema.

\subsection{Los hiperrealistas y la vuelta a la perspectiva}

A mediados de los años 60, surge en medio de las corrientes que buscaban el arte en la huida de la realidad o en el vano intento de cambiarla, un grupo de artistas que, de una u otra forma, vuelve a refugiarse en "lo real". Los hiperrealistas representan una obsesión exagerada por plasmar con exactitud más que fotográfica la realidad que les rodea, conocida solo en apariencia (experiencia óptica), manipulable y siempre engañosa. Howard Kanovitzloresume en la frase "Todo es como es, y sin embargo es distinto de como se nos aparece". (Coke, 1972).

La mayoría de los hiperrealistas o fotorrealistas abordaban sus pinturas a partir de literalidad de las imágenes fotográficas realizadas casi siempre por ellos mismos o tomadas de los medios de comunicación. Frai Gertsch (1930), por ejemplo, definió su proyecto artístico como el resultado de cinco etapas consecutivas: "percibir, ver, fotografiar, elegir y pintar". Por su parte, Robert Cottingham (1935), autor de espectaculares cuadros de letreros fragmentados, utiliza también la cámara fotográfica para, en sus propias palabras, "hallar, aislar y enlazar los detalles en una obra pictórica". De este modo, el pintor hiperrealista ejercía, en primer lugar, una 
mirada de fotógrafo -mirando el mundo desde la fotografía-, para después "elegir" y traducir en términos pictóricos la imagen original.

La clave estética de estos artistas era pues transcribir en términos pictóricos y con la mayor neutralidad posible conceptos eminentemente fotográficos (enfoque y desenfoque, precisión y detalle, profundidad de campo y plano focal) para provocar la perplejidad del espectador y crear una nueva categoría de representación de la realidad que, a pesar de todo, seguía siendo tributaria de las leyes de la óptica y de la perspectiva central.

\subsection{Futuro inmediato. El 3-d}

Hasta ahora y desde el Renacimiento, hemos considerado la composición en un único plano y cuando hemos necesitado crear profundidad, la hemos "fingido" o inventado gracias a los indicadores de profundidad. Pero el 3D trabaja en capas y será necesario componer cada una de ellas, puesto que el punto de vista se desplaza sobre el eje Z. Así es necesario reformular el modo en que tratamos la profundidad de campo, ya que ahora no sólo depende de las tres condiciones clásicas (diafragma de trabajo, distancia focal de la lente y distancia sujeto-cámara) sino que entran en juego, el ángulo paraláctico y el punto de convergencia de ambas lentes.

Será necesario prestar mucha atención a la profundidad de campo y las relaciones de escala entre las capas del conjunto de cada plano, y al raccord de esa profundidad entre los sucesivos planos. Ya se han podido ver chocantes diferencias de profundidad entre planos cercanos y planos generales en la misma secuencia que, vistos en la versión $2 \mathrm{~d}$ pasan desapercibidos pero en cuanto nos ponemos las gafas producen una sensación extraña que nos distancia de la acción.

No se trata solamente de rodar en 2D con dos cámaras, sino que cambian la narrativa, el modo de rodar y de montar. No se piensa en "multiplanos" sino en volúmenes, lo que hace que las proporciones de los encuadres tengan que jugar con el tamaño de los objetos y las relaciones de distancia entre ellos.

Por lo visto hasta ahora, los primeros planos en 3D no funcionan del todo bien, pues se produce un efecto de separación excesivo entre los planos de la nariz y las orejas que resulta antiestético. Las proporciones en los planos generales cortos son mas controlables y los PG abiertos corren el riesgo de que las cosas se vean demasiado pequeñas aunque son los que dan mejores resultados.

Naturalmente depende de cada situación la elección de los valores de los dos parámetros que definen el 3D: la interaxial y la convergencia. Se realiza un mapa de profundidad que define los extremos de esta y mantiene la coherencia de la geometría estereoscópica entre planos sucesivos. Es importante que entre plano y plano no haya un salto estereoscópico del centro de interés. 


\section{Conclusiones}

Desde que los pintores del Quattrocento asumen la perspectiva central y comienzan a pintar tal como se ve, una pintura será considerada buena o mala según su mayor o menor acercamiento a los esquemas ópticos del sistema perceptivo humano. De ahí el incuestionable triunfo de la perspectiva central cuando es propuesta por Brunelleschi.

Sin embargo, cuando aparece la fotografía, el pintor, que hasta ese momento, había sido comisionado por la sociedad para, gracias a su habilidad -no hay que olvidar que durante muchos siglos la pintura fue considerada una artesanía y no un Arte- ser el testigo y dejar testimonio de la realidad, es empujado a buscar otros caminos, precisamente por la tecnología que había ocultado emplear, cuando ésta llega a su máxima perfección.

Mientras la pintura solo podía afirmar la probabilidad en cuanto a la corrección de su reproducción, la fotografía podía invocar la veracidad. La fotografía era reproducción, no una mera imitación, de la realidad. Con ello introdujo en el arte un principio de realidad que la hacía superior a la pintura, siempre avalada por la correcta perspectiva.

Se abre entonces un paréntesis en la historia de un arte que, pese a tener el deber de testimoniar no había pasado, en muchos casos, de interpretar. Este paréntesis sólo va a ser cerrado a finales del siglo XX, con la aparición de los sistemas digitales de manipulación de imágenes, que vuelven a hacer posible, ya en un entorno en que el arte está plenamente democratizado, la manipulación creativa de la realidad. La pregunta, llegados a este punto, sería: ¿Seguirá, en los nuevos tiempos de la imagen digital y del 3-D, siendo la perspectiva de Brunelleschi la forma básica de representación de la realidad? La respuesta la da otra pregunta: ¿Vamos a seguir teniendo dos ojos?

\section{Referencias}

BARTHES, R. (1989). La Cámara Lúcida. Nota Sobre La Fotografía. Paidós. Barcelona.

BAYO MARGALEF, J. (1987). Percepción Y Desarrollo Cognitivo Y Artes Visuales. Anthropos. Barcelona.

BENJAMIN, W. (1987). Pequeña Historia De La Fotografía. Madrid. Taurus.

BERGER, J. (1998). Modos De Ver. Gustavo Gili. Barcelona.

BRUCE, V; GREEN, P. R. (1984). Percepción Visual. Paidós. Barcelona.

BRUSATIN, Manlio. (1992). Historia De Las Imágenes. Julio Ollero Editor. Madrid.

BURCH, Noel. (1995). El Tragaluz Del Infinito. Cátedra. Madrid.

COKE, Van Deren. (1972). The Painter And The Photography. Albuquerque. 
University Ofnew México.

CRICK, Francis. (1994). La búsqueda científica del alma. Debate. Madrid.

DA VINCI, Leonardo Y ALBERTI, L. B. (1999). EI Tratado De La Pintura y los tres Libros que sobre el mismo arte escribió.Facsimil de la ed. De 1784. Alta Fulla. Barcelona.

DAMISCH, Hubert. (1997). El origen de la Perspectiva. Madrid. Alianza Ed.

DEL CAMPO Y FRANCÉS, Angel. (1978). La Magia de Las Meninas. Ediciones y Publicaciones, S. A. Madrid,

FEIST, Peter H. (1996). El Impresionismo en Francia 1860-1920. Benedikt Taschen.

FREUND, Gisele. (1976). La Fotografía Como Documento Social. Gustavo Gili.

FRISBY, L. P. (1987). Del ojo a la visión. Alianza. Madrid.

FRIZOT, Michel (Edit): (1998). A New History of Photography. Kónemann.

GALLEGO, Julian. (1995). Diego Velázquez. Alianza Editorial. Madrid.

GAULTIER, G. (1996). Veinte lecciones sobre la imagen y el sentido. Madrid. Cátedra.

GERNSHEIM, Helmut Y Alison. (1967). Historia gráfica de la Fotografía. Omega.

GIOSEFFI, D. Canaletto. (1959). II Cuaderno Delle Gallerie Veneziane El' Impiego Della Camera Ottica. Trieste.

GOMBRICH, E. H. (1998). Arte E llusión. Debate. Madrid.

HARTMANN, Sadakichi. (1991).Critical Modernist. Ed By Jane Calhoum Weaver.

KEIM, Jean A. (1971). Historia De La Fotografía. Oikos- Tau. Barcelona.

NEWALL, Beaumont. (1983). Historia De La Fotografía. Gustavo Gili.

NOCHLIN L. (1991). EI Realismo, Alianza Editorial. Madrid.

PEDOE, Dan. (1999). La Geometría En El Arte. Gustavo Gili. Barcelona.

POLLAK, Peter. (1997). The Picture History Ofphotography. Harry N. Abrams. New York.

POTONNIÉE, Georges. (1940). Cent ans de photographie, 1839-1939. Societe D'editions Geographiques. Paris.

PUPPI, L. (1981). La Obra Pictórica Completa De Canaletto. Noguer-Rizzoli. Barcelona. 
José-María Castillo-Pomeda y Miguel Angel Ortiz Sobrino.

SCHARF, Aaron. (1969). Art and photography. The Penguin books. Baltimore.

TORÁN, Enrique (1998).Tecnología audiovisual II. Síntesis. Madrid 